\title{
CARACTERIZAÇÃO HIDROAMBIENTAL COMO INDICADOR DE QUALIDADE DE ÁGUA EM NASCENTES
}

\author{
Francielle Rodrigues de Oliveira \\ Universidade Federal do Espírito Santo, Programa de Pós-Graduação em Ciências Florestais, \\ Jerônimo Monteiro, ES, Brasil \\ francielle.loyal@gmail.com
}

Universidade Federal Roberto Avelino Cecílio Agrárias e Engenharias, Jerônimo Monteiro, ES, Brasil racecilio@yahoo.com.br

Sidney Sara Zanetti Universidade Federal do Espírito Santo, Departamento de Ciências Florestais e da Madeira, Centro de Ciências Agrárias e Engenharias, Jerônimo Monteiro, ES, Brasil sszanetti@yahoo.com.br

Fabrina Teixeira Ferraz Universidade Federal de Lavras, Programa de Pós-Graduação em Engenharia Florestal, Lavras, MG, Brasil fabrina.ferraz@hotmail.com

\begin{abstract}
RESUMO
A potabilidade da água para o consumo humano influencia a saúde e a qualidade de vida das populações. As nascentes representam a principal fonte de abastecimento das famílias do Assentamento Florestan Fernandes (AFF), localizado no Sul do Estado do Espírito Santo. Todavia, a supressão das florestas nativas do AFF e ausência de proteção recomendada colocam em risco a conservação e perenidade das nascentes, e podem comprometer a potabilidade da água. O objetivo deste estudo foi avaliar a qualidade das águas de nascentes com diferentes características ambientais no AFF. Selecionou-se oito nascentes e realizou-se coletas periódicas e análises laboratoriais para avaliar os parâmetros físicos, químicos e microbiológicos da água. Ademais, foi calculado o Índice de Impacto Ambiental em Nascentes (IIAN), para identificar o grau de impacto ambiental na área de contribuição de cada nascente. Os resultados dos parâmetros de qualidade da água, mostraram que há inconformidade com a Portaria de consolidação n5/2017 do Ministério da Saúde e Resolução do CONAMA 357/05. O IIAN mostrou que 25\% das nascentes foram enquadradas como "bom", 37,5\% como "Razoável, outras 25\% classificadas como "ruim" e 12,5\% como "Péssimo". Concluiu-se que o uso e ocupação do solo, bem como seu manejo influenciam na qualidade da água.
\end{abstract}

Palavras-chave: Potabilidade. Uso e ocupação da terra. Reforma agrária. Degradação ambiental. Gestão de recursos hídricos.

\section{HYDROENVIRONMENTAL CHARACTERIZATION AS A WATER QUALITY INDICATOR IN SPRINGS}

\begin{abstract}
The potability of water for human consumption influences the health and quality of life of populations. The springs represent the main source of supply for the families of the Florestan Fernandes Settlement (AFF), located in the south of the state of Espírito Santo. However, the suppression of native forests the AFF and the lack of recommended protection endanger the conservation and perenniality of springs, and may compromise water potability. The objective of this study was to evaluate the water quality of springs with different environmental characteristics in AFF. Eight springs were selected and periodic collections were performed and laboratory analyzes to evaluate the physical, chemical and
\end{abstract}


microbiological parameters of the water. In addition, the Spring Environmental Impact Index (IIAN) was calculated to identify the degree of environmental impact on the contribution area of each spring. The results of water quality parameters, showed that there is non-conformity with the consolidation ordinance $n^{\circ} 5 / 17$ of the Ministry of Health and CONAMA Resolution $357 / 05$. The IIAN showed that $25 \%$ of the springs were classified as "good", $37.5 \%$ as "reasonable", another $25 \%$ classified as" bad" and $12.5 \%$ as "terrible". It was concluded that the use and occupation of the soil, as well as its management influence the water quality.

Keywords: Potability. Land use and occupation. Agrarian reform. Environmental degradation. Water resources management.

\section{INTRODUÇÃO}

A água está entre os mais importantes recursos disponíveis na natureza e é considerada um requisito básico à manutenção da vida. Consiste em elemento essencial para a produção e preparo de alimentos, para as atividades higiênicas, para a geração de energia, para a manutenção de ecossistemas e para o desenvolvimento de florestas, agricultura e criação de animais, dentre outros. Dada a importância desse recurso natural, considera-se que a escassez hídrica ameaça à saúde humana, a segurança alimentar, a produção de energia e a integridade ambiental. A expansão populacional, o aumento das atividades industriais e agrossilvipastoris, e a intensificação da degradação ambiental, associados às mudanças climáticas, ameaçam os recursos hídricos do planeta. No que se refere aos impactos do setor rural, a falta de planejamento e manejo adequado do uso da terra, quando somados à compactação do solo pela pecuária, à excessiva irrigação agrícola, o uso abusivo de agrotóxicos e a não preservação de matas ripárias, ameaçam de forma direta e indireta o recurso hídrico (REISSLER e MANZIONE,2016) e, consequentemente, afetam negativamente a quantidade e qualidade da água.

A qualidade de água é influenciada pelos elementos naturais (geologia, vegetação, solos e clima) e, sobretudo, pelo conjunto de atividades antrópicas, de forma a alterar sensivelmente os processos biológicos, físicos e químicos dos recursos hídricos. A degradação dos mananciais compromete sua utilização para abastecimento doméstico, em especial de pequenos núcleos populacionais no meio rural, devido a alterações no sabor e odor da água, além do aumento excessivo de elementos químicos provenientes do uso de insumos agrícolas (MERTEN e MINELLA, 2002). Para identificação das alterações ocorridas nos recursos hídricos, suas possíveis causas, e avaliar a potabilidade da água, é necessário um monitoramento dos parâmetros, a fim de confrontá-los com as legislações em vigor e garantir que o consumo da água esteja dentro dos padrões para o abastecimento público.

No Brasil, em especial no Espírito Santo, é comum encontrar atividades agropecuárias sendo desenvolvidas na área situada no entorno de nascentes, o que não só se caracteriza como uma infração ao Código Florestal Brasileiro, exceto quando consideradas Áreas de Preservação Permanente (APP) consolidadas, como coloca em risco a conservação e a qualidade da água. Diante do cenário de crescente escassez de água de qualidade, tem-se buscado estratégias para uma gestão sustentável dos recursos hídricos. A prioridade é garantir a sustentabilidade da água potável para consumo humano. A Agência Nacional de Águas - ANA (2013) propõe três soluções fundamentais para proteger, melhorar a qualidade e a quantidade de água: prevenir a poluição, tratar a água poluída e restaurar os ecossistemas. Compartilhando da mesma afirmativa, Marciano et al. (2016) sugerem que a preservação das nascentes é uma medida simples, de baixo custo, que previne a poluição, melhora a qualidade da água e restaura o ecossistema. Por isso, trabalhos de campo que visam à proteção, recuperação e/ou preservação de nascentes são tão necessários para evitar problemas de disponibilidade futura.

O Assentamento Florestan Fernandes (AFF), localizado no Sul do Espírito Santo, enfrenta problemas com a falta de chuvas e a diminuição de água disponível para a irrigação e, sobretudo, para uso doméstico. $O$ Assentamento faz uso da água proveniente das nascentes para as mais diversas finalidades domésticas, incluindo beber, cozinhar e higiene pessoal. Logo, é indispensável que a água seja de qualidade. Sabe-se 
que o estado de conservação de uma nascente está relacionado ao relevo e ao grau de conservação do solo e da vegetação, os quais dependem do uso e ocupação de terras pela atividade antrópica nas regiões à montante destas. Fatores como a supressão da vegetação, as atividades agropecuárias inadequadas e o uso indevido do solo potencializam o processo de degradação de nascentes e dos cursos d'água, interferindo na qualidade e quantidade da água de uma bacia hidrográfica (BOMFIM et al., 2015). A identificação das causas e da magnitude da degradação da qualidade da água de uma nascente permitem estabelecer procedimentos de avaliação de impactos ambientais, e adotar técnicas que harmonizem a agricultura familiar sustentável dentro dos assentamentos rurais e a otimização de uso da água.

Segundo ANA (2013), pesquisas relacionadas aos aspectos qualitativos da água receberam menos investimento, apoio científico e atenção do público que a quantidade volumétrica, mesmo sendo de igual importância. Portanto, ressalta-se que um monitoramento contínuo da qualidade da água e a quantificação das alterações ambientais são bons indicadores de falhas no manejo e uso do solo, e representam formas eficientes para minimizar os efeitos dos impactos negativos. Neste sentido, estudos têm sido direcionados à identificação dos usos do solo e sua relação com os parâmetros de qualidade da água (BERTOSSI et al., 2013; MARMONTEL; RODRIGUES, 2015; MACHADO et al., 2016; SIMEDO et al., 2018; RODRIGUES et al., 2019).

Dentro deste contexto, considera-se importante, para o AFF, a condução de estudos objetivando, primeiramente, caracterizar a qualidade de suas águas e áreas de contribuição das nascentes, quanto ao tipo e grau de conservação. Tais práticas consistirão em subsídios para analisar os efeitos do uso do solo nas APPs de nascentes sobre a qualidade das águas e identificar as principais fontes geradoras de impactos ambientais, a fim de propor ou intensificar práticas destinadas à sua melhoria.

\section{METODOLOGIA}

A hipótese que norteia o trabalho é a de que a qualidade da água sofre influência dos impactos ambientais das nascentes e o uso e cobertura do solo da área à sua montante. Para testar essa hipótese realizou-se um estudo no referido assentamento rural, dividido em duas etapas. No primeiro momento realizou-se coletas de amostras de água das nascentes, bem como suas análises qualitativas. Na segunda etapa, aplicou-se a avaliação macroscópica dos impactos ambientais.

\section{ÁREA DE ESTUDO}

As nascentes em estudo localizam-se na área do Assentamento Florestan Fernandes, localizado no sul do Espírito Santo, nos municípios de Guaçuí e São José do Calçado, pertencente à bacia do rio Itabapoana (Figura 1).

\section{CARACTERIZAÇÃO HIDROAMBIENTAL}

A pesquisa foi desenvolvida analisando os parâmetros de qualidade ambiental das nascentes, conforme metodologia proposta por Gomes et al. (2005), replicada por diversos autores, tais como: França Junior e Villa, 2013; Oliveira et al. 2013;Belizário,2015; Corrêa et al., 2016; Torres, 2016; Leal et al., 2017; Soares e Troleis, 2017; Silva et al. 2018; Beckauser et al. 2019 . Para cumprimento dos objetivos deste estudo foram utilizados procedimentos metodológicos de caráter exploratório e descritivo, realizados por meio da pesquisa de campo e observação in loco em dezembro de 2017. A técnica consiste na avaliação macroscópica e comparativa de alguns parâmetros (elementos-chave) na identificação de impactos ambientais e suas consequências nas nascentes. Resumidamente, este procedimento verifica de forma qualitativa o grau de proteção em que as nascentes se encontram, atribuindo notas aos parâmetros observados, conforme Quadro 1.

\begin{tabular}{|c|c|c|}
\hline Caminhos de Geografia & Uberlândia-MC & v. 21, n. 74 \\
\hline
\end{tabular}


Figura 1 - Localização das nascentes selecionadas para o estudo no assentamento Florestan Fernandes, Espírito Santo, Brasil.

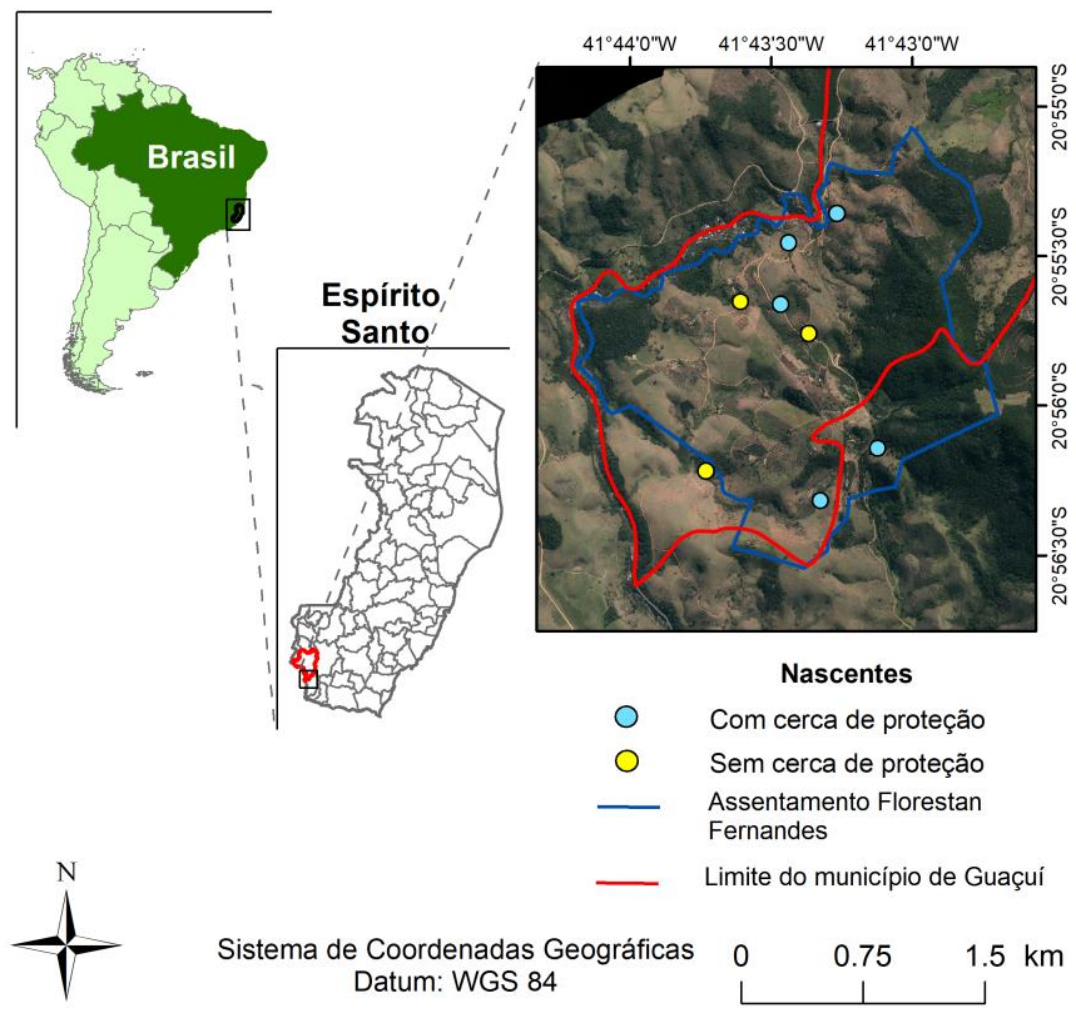

Fonte - Base de dados obtida junto ao Sistema Integrado de Bases Georreferenciadas do estado do Espírito Santo - GEOBASES, Instituto Nacional de Colonização e Reforma Agrária - INCRA. Elaborado pelos autores.

Quadro 1 - Parâmetros utilizados na avaliação macroscópica de nascentes.

\begin{tabular}{|l|ccc|}
\hline \multirow{2}{*}{ Parâmetro macroscópico } & \multicolumn{3}{c|}{ Classificação } \\
\cline { 2 - 4 } & Ruim & Médio & Bom \\
\hline Cor da água & (1ponto) & (2 pontos) & (3 pontos) \\
Odor da água & Escura & Clara & Sem odor \\
Lixo ao redor da nascente & Forte & Com odor & Ausente \\
Materiais flutuantes (lixo na água) & Muito & Pouco & Ausente \\
Espumas & Muito & Pouco & Ausente \\
Óleos & Muito & Pouco & Ausente \\
Esgoto & Muito & Pouco & Ausente \\
Vegetação na APP & Presença & Evidência & Presente \\
Uso pela fauna & Degradada ou ausente & Alterada & Ausente \\
Uso antrópico & Presença & Evidência & Não há \\
Proteção (cerca) & Constante & Esporádico & Presente, mas com \\
Áreas construídas & Ausente & Presente, mas com & difícil acesso \\
\hline
\end{tabular}

Fonte - Adaptada de Gomes et al. (2005); Felippe e Magalhães Junior. (2012); e Leal et al. (2017). 
Para interpretação do Índice de Impacto Ambiental em Nascentes (IIAN), as notas dos fatores determinantes para a avaliação da qualidade ambiental são somadas e convertidas em classes de qualidade. Assim, as nascentes são categorizadas quanto ao grau de conservação em relação aos impactos presentes em: A - ótimo (IIAN entre 36 e 34 pontos); B - bom (IIAN entre 33 e 31); C - razoável (IIAN entre 30 e 28); D - ruim (IIAN entre 27 e 25) e $E$ - péssimo (IIAN abaixo de 25).

\section{PROCEDIMENTO DE COLETAS, AMOSTRAGEM E ANÁLISE DE ÁGUA}

Foram realizadas quatro coletas entre o mês de março de 2017 a outubro de 2017 nas oito nascentes. As datas das coletas foram planejadas de forma a acompanhar a tendência da qualidade da água durante 0 ano. As coletas foram executadas sempre pela manhã e em dias sem chuva.

Os procedimentos de amostragem seguiram as normas ABNT NBR 9898:1987 (ASSOCIAÇÃO BRASILEIRA DE NORMAS TÉCNICAS - ABNT, 1987). Utilizaram-se dois frascos de polietileno de $500 \mathrm{ml}$ para cada coleta em cada nascente, somando 1 litro de água amostral, para atender as análises laboratoriais, totalizando ao final da pesquisa quatro amostras por nascente. Os frascos foram submetidos à esterilizações prévias com água quente e, durante as coletas realizou-se a ambientação com uma tríplice lavagem com a própria água do local amostrado.

Os parâmetros analisados para caracterização físico-química e microbiológica foram: coliformes totais, coliformes termotolerantes, condutividade elétrica, Demanda Bioquímica de Oxigênio - DBO, fósforo total, nitrogênio total, oxigênio dissolvido, $\mathrm{pH}$, sólidos totais, sólidos dissolvidos, sólidos suspensos, temperatura, turbidez, e os minerais $\mathrm{Ca}, \mathrm{Mg}$ e Fe.

As análises de oxigênio dissolvido e temperatura foram realizadas em campo utilizando oxímetro portátil (Hanna, HI 9146). Os demais parâmetros foram analisados em laboratório, utilizando equipamentos específicos, como descritos no Quadro 2.

Quadro 2 - Parâmetros analisados e os respectivos equipamentos laboratoriais utilizados.

\begin{tabular}{|cc|}
\hline Parâmetro & Equipamento \\
\hline $\mathrm{pH}$ & Potenciômetro de bancada (Marconi, PA 200) \\
$\mathrm{CE}$ & Condutivímetro de bancada (Hanna, HI 2300) \\
Turbidez & Turbidímetro de bancada (Hanna, HI 98703) \\
$\mathrm{Ca}, \mathrm{Mg}$ e Fe & Equipamento multiparâmetros (Hanna, HI 83200) \\
Fósforo total, e Nitrogênio total & Equipamento multiparâmetros (Hanna, HI 83214) \\
Coliformes totais e termotolerantes & COLIPAPER (Alfakit (Cód:65)) \\
Série de sólidos & Método gravimétrico \\
DBO & Método da DBO a 20 C - durante 5 dias \\
\hline
\end{tabular}

Fonte - Os autores.

Calculou-se a média entre as quatro coletas para cada parâmetro analisado, sendo os resultados representados em tabelas para apreciação e análise do comportamento, de modo a permitir o enquadramento na legislação.

Em razão dos diferentes usos da água no assentamento, especialmente abastecimento das famílias e irrigação dos cultivos, os valores encontrados nas análises foram confrontados com as seguintes normativas: Portaria de consolidação ํㅡ 5/17 do Ministério da Saúde, que confere um padrão de potabilidade da água para o consumo humano, visto que a água das nascentes é usada sem um tratamento prévio ou desinfecção (BRASIL, 2017); e Resolução do Conselho Nacional do Meio Ambiente - 
CONAMA no 357/05 (classe 1, 2, 3 e 4), para verificar as condições de preservação ambiental na qual se encontram as nascentes. Os limites permitidos nas legislações supracitadas são apresentados no Tabela 1.

Tabela 1 - Padrões normativos para qualidade da água referentes aos parâmetros avaliados no estudo.

\begin{tabular}{|c|c|c|}
\hline Parâmetros & Portaria $n=5 / 17$ & $\begin{array}{c}\text { Resolução n³57/05 - } \\
\text { Classe II }\end{array}$ \\
\hline OD (mg L $\left.{ }^{-1}\right)$ & * & $\geq 5$ \\
\hline Temperatura $\left({ }^{\circ} \mathrm{C}\right)$ & * & * \\
\hline $\mathrm{pH}$ & 6,0 a 9,5 & 6,0 a 9,0 \\
\hline Col. totais (NMP ${ }^{(1)} 100 \mathrm{~mL}^{-1}$ ) & Ausência & * \\
\hline Col. fecais (NMP100 mL-1) & Ausência (2) & $\leq 1000^{(3)(4)}$ \\
\hline $\mathrm{DBO}\left(\mathrm{mg} \mathrm{L}^{-1}\right)^{(5)}$ & * & $\leq 5$ \\
\hline Nitrato $\left(\mathrm{mg} \mathrm{L}^{-1}\right)$ & $\leq 10$ & $\leq 10$ \\
\hline $\mathrm{N}$ amoniacal $\left(\mathrm{mg} \mathrm{L}^{-1}\right)$ & $\leq 1,5$ & $\leq 3,7^{(6)}$ \\
\hline $\mathbf{N}$ total $\left(\mathrm{mg} \mathrm{L}^{-1}\right)$ & * & * \\
\hline$P$ total $\left(\mathrm{mg} \mathrm{L}^{-1}\right)$ & * & $\leq 0,1$ \\
\hline $\mathrm{Fe}\left(\mathrm{mg} \mathrm{L}^{-1}\right)$ & 0,3 & 0,3 \\
\hline $\mathrm{Ca}\left(\mathrm{mg} \mathrm{L}{ }^{-1}\right)$ & * & * \\
\hline$M g\left(m g L^{-1}\right)$ & * & * \\
\hline Turbidez (UNT) ${ }^{(7)}$ & $\leq 5$ & $\leq 100$ \\
\hline $\mathrm{Ce}\left(\mu \mathrm{s} \mathrm{cm}^{-1}\right)$ & * & * \\
\hline Sólidos totais $\left(\mathrm{mg} \mathrm{L}^{-1}\right)$ & * & * \\
\hline Sólidos dissolvidos (mg L $\left.{ }^{-1}\right)$ & $\leq 1000$ & $\leq 500$ \\
\hline Sólidos suspensos $\left(\mathrm{mg} \mathrm{L}^{-1}\right)$ & * & * \\
\hline
\end{tabular}

(*) Valor não especificado na referida normativa; (1) Número mais provável; (2) Água para consumo humano em toda e qualquer situação, incluindo proveniente de poços, minas e nascentes; (3) Para uso de recreação de contato primário deverá ser obedecida a Resolução CONAMA № 274 de 2000; (4) Esse valor não deverá ser excedido em $80 \%$ ou mais de pelo menos seis amostras coletadas no período de um ano, com frequência bimestral; (5) DBO 5 dias a 20을 (6) Para $\mathrm{pH} \leq 7,5$ (situação encontrada nesse trabalho); (7) Unidade Nefelométrica de Turbidez.

Fonte - (BRASIL, 2004, 2017).

Os padrões de qualidade dos parâmetros analisados neste trabalho (Tabela 1) são referentes à classe 2, na qual encontra-se os corpos hídricos estudados. Apesar das referidas normas não estabelecerem padrões específicos para os parâmetros temperatura, cálcio, magnésio, sólidos totais e suspensos, suas determinações são importantes para conferir aceitação para uso humano. Os resultados de nitrogênio total nesse estudo foram confrontados com os padrões de nitrito, nitrato e amônia, por não existir nas referidas normas os padrões específicos para N Total.

\section{ANÁLISE ESTATÍSTICA}

Os dados oriundos dessa pesquisa comportam-se de forma complexa, por apresentarem-se formados por diversas variáveis, medidas em diferentes escalas e unidades, e por serem obtidos de locais diferentes. Devido a essa complexidade dinâmica, que torna difícil a compreensão do seu comportamento, utilizou-se, dentre as técnicas de análise multivariada, a análise de agrupamento. Essa análise possibilita agrupar variáveis similares, investigar a dependência entre variáveis agrupadas, e relacionar variáveis observadas, objetivando predizer uma ou mais variável, além de construir testes de hipóteses (GOMES e CAVALCANTE, 2017).

\begin{tabular}{llllll}
\hline Caminhos de Geografia & Uberlândia-MG & v. 21, n. 74 & Abr/2020 & p. 276-294 Página 281
\end{tabular}


Para efeito deste estudo, a análise de agrupamento fez-se necessária para obter estatisticamente grupos de nascentes que poderiam se comportar de forma semelhante, usada apenas como uma técnica exploratória. Utilizou-se o programa computacional livre e gratuito $\mathrm{R}^{\circledR} 3.4 .2$ para processamento dos dados e obtenção dos agrupamentos, cumprindo-se três etapas: padronização; escolha do coeficiente de semelhança; e escolha da estratégia de agrupamento. O algoritmo de agrupamento utilizado para definição dos agrupamentos foi o método Ward.

\section{RESULTADOS E DISCUSSÃO}

\section{CARACTERIZAÇÃO HIDROAMBIENTAL}

As características observadas nas oito nascentes são descritas no Quadro 3 e apresentadas na Figura 2.

\section{Quadro 3 - Características das nascentes selecionadas para estudo.}

(1) A água apresentou-se incolor, sem odor, sem espumas e sem óleos. Não observou-se a presença de esgoto, lixo ao redor da nascente e nem materiais flutuantes na água. O estado de conservação da vegetação foi considerado de baixa degradação. A nascente é protegida por cerca bem conservada. $A$ água é usada pelas famílias e há evidências de uso por animais silvestres.

(3) A água apresentou coloração "barrenta" clara, sem odor evidente, sem espumas e sem óleos na superfície. Não detectou-se presença de esgoto, espumas, óleos e lixo. Vegetação formada por pastagem e poucos indivíduos arbustivos. Encontrouse pegadas de animais próximas à área. A nascente possui proteção via cercamento padrão do Programa. Localizada às margens da estrada vicinal do assentamento.

(5) A cor da água apresentava-se levemente alterada, inodora, sem espumas, lixo, óleos na superfície e esgoto. A nascente é protegida por telhas de amianto e fica sombreada pela vegetação arbórea-arbustiva com presença de espécies frutíferas. Não há utilização e nem presença de animais. A nascente é cercada, mas permite a entrada de humanos que fazem uso da água.

(7) A água é incolor e inodora. Não observou-se lixo ao redor da nascente, nem materiais na água, nem espumas ou óleos. A vegetação antropizada no entorno é composta por espécies arbóreasarbustivas, gramíneas e cultivos diversos, sobretudo olericultura. Encontra-se perto da residência, mas sem evidência de esgoto na área. Área não cercada.
(2) Cor esverdeada e forte odor. Sem espumas e óleos na superfície, ausência de esgoto e de lixo na área circundante da nascente. Apesar de não detectar lixo na água, observou-se elevada quantidade de pequenos galhos e folhas. Vegetação secundária antropizada, com presença de espécies invasoras próxima a nascente. Cercada e localizada abaixo da área declivosa de um curral.

(4) Cor e odor da água alterados, localizada próxima a residências, mas sem indícios de esgotos, espumas, óleos na superfície, lixo no entorno ou material flutuante. Possui cerca e a vegetação é formada por pastagem em todo o entorno. O local onde está inserida é a parte mais baixa de onde há constante presença de animais, porém sem acesso à água.

(6) A água da nascente 06 é acumulada em um açude. Apresenta-se com cor alterada e odor fraco. Ausência de lixo na área circundante, de óleos e espumas. Observou-se uma pequena quantidade de material flutuante na água (garrafa PET). Não possui cercamento e permite a entrada de pessoas e uso da água pelo do gado. Ausência da faixa vegetada consistindo unicamente em pastagem.

(8) A área não é cercada e está inserida na área de pastagem com constante presença de bovinos. A cor da água apresentou-se alterada e sem odor, sem espumas e óleos na superfície. Não há rede de esgoto doméstico próximo do local e não constatou-se material flutuante ou lixo acumulado no entorno. A vegetação é composta predominantemente por pastagem de uso intensivo, solo exposto e presença de espécies arbustivas invasoras.

(1); (2); (3); (4); (5); (6); (7); (8): Nascentes estudadas

Fonte - Os autores.

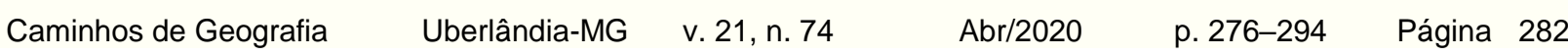


Figura 2 - Características do entorno das nascentes e pontos de coletas.
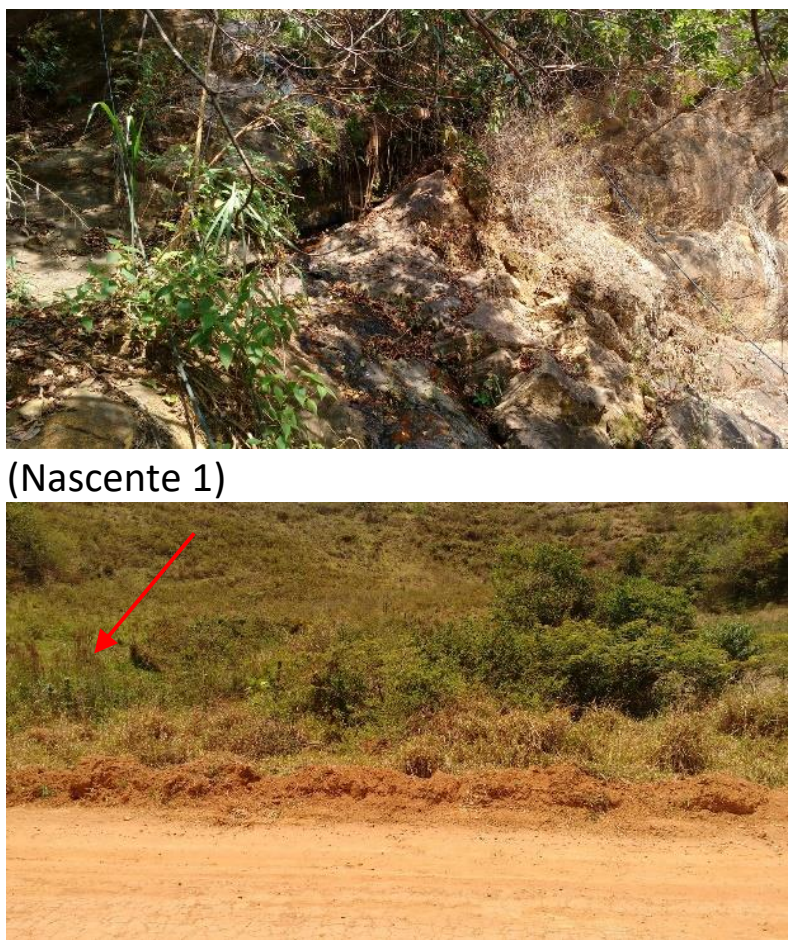

(Nascente 3)

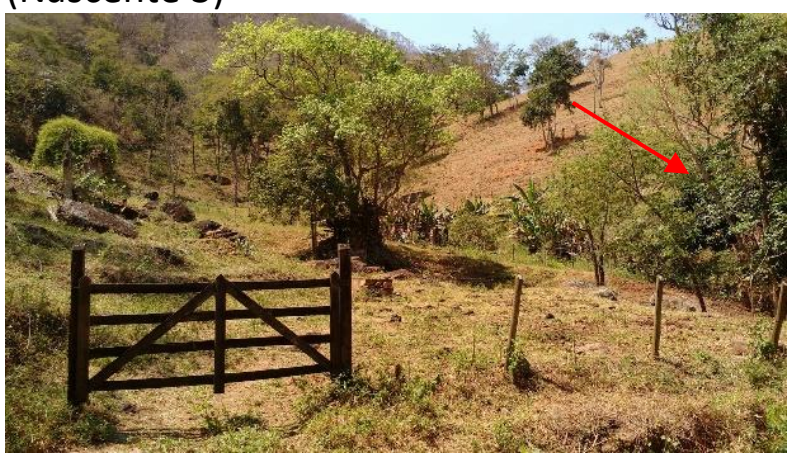

(Nascente 5)

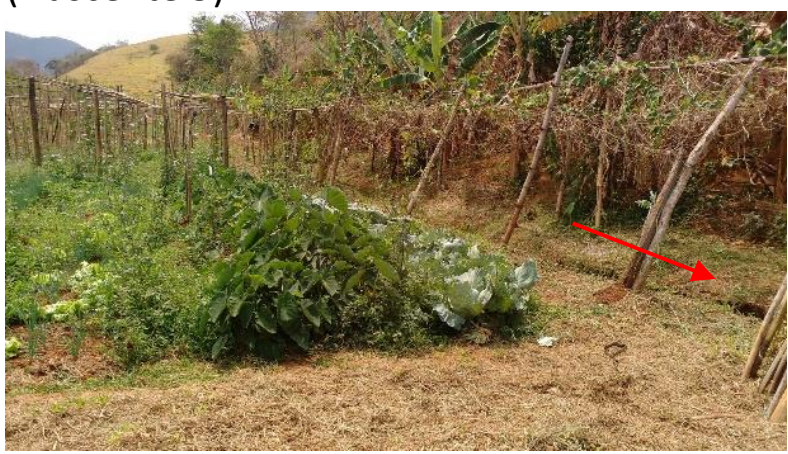

(Nascente 7)
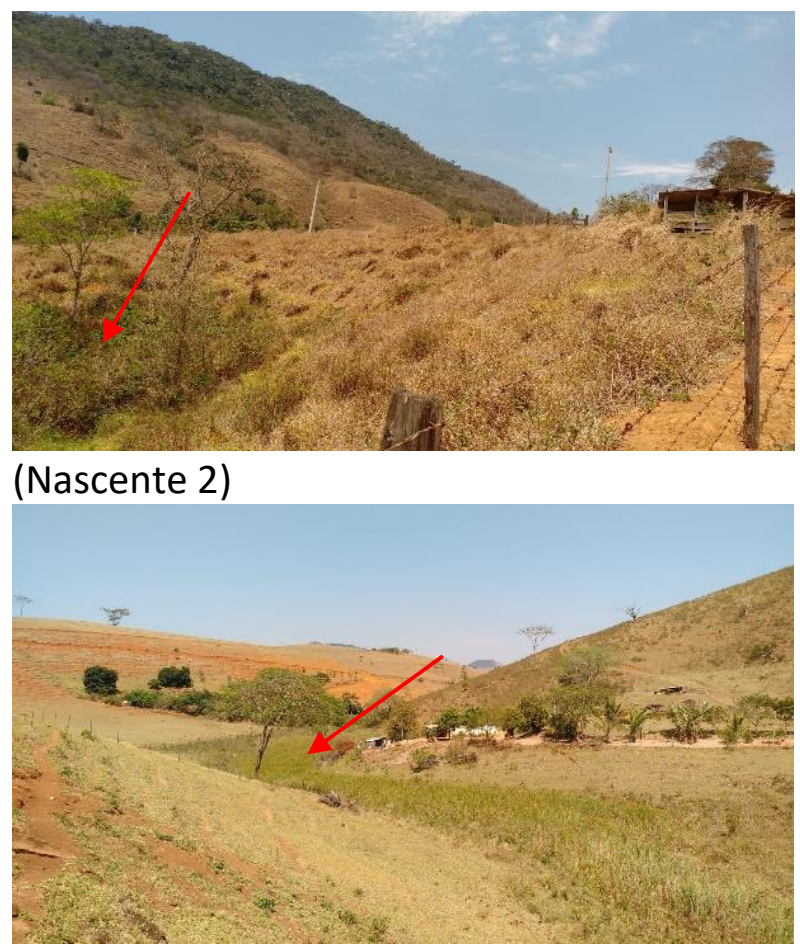

(Nascente 4)

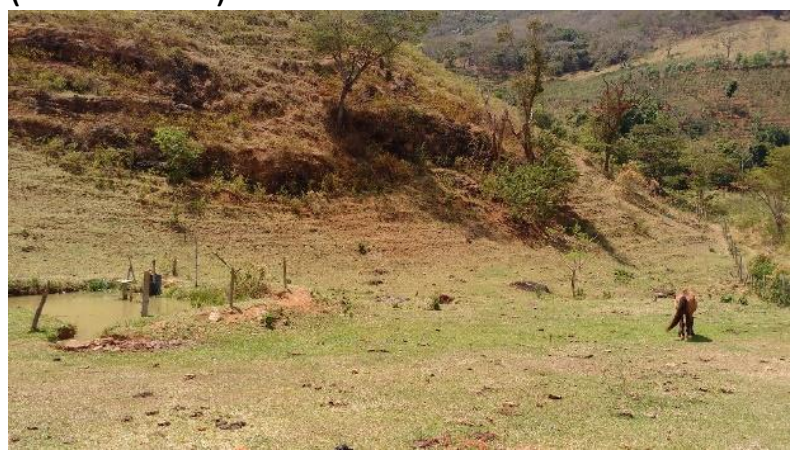

(Nascente 6)

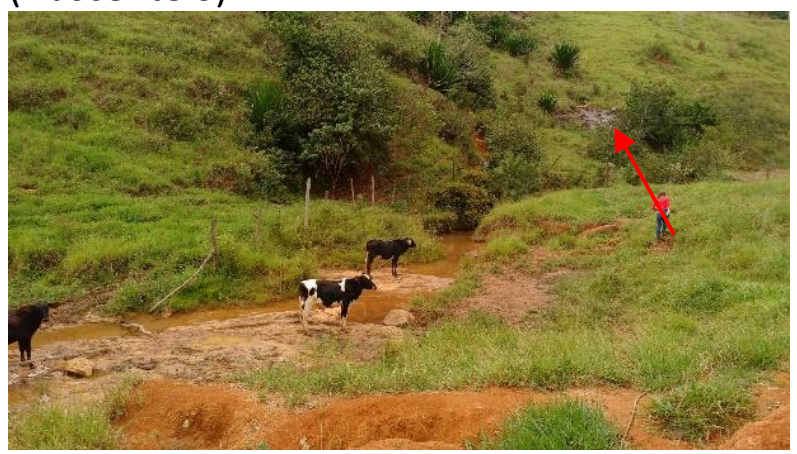

(Nascente 8)

Fonte - arquivo próprio. Trabalho de campo 2017. 
Na Tabela 2 são apresentados os resultados obtidos após a aplicação do protocolo para a caracterização ambiental das nascentes.

Tabela 2 - Caracterização hidroambiental das nascentes e seus respectivos graus de preservação.

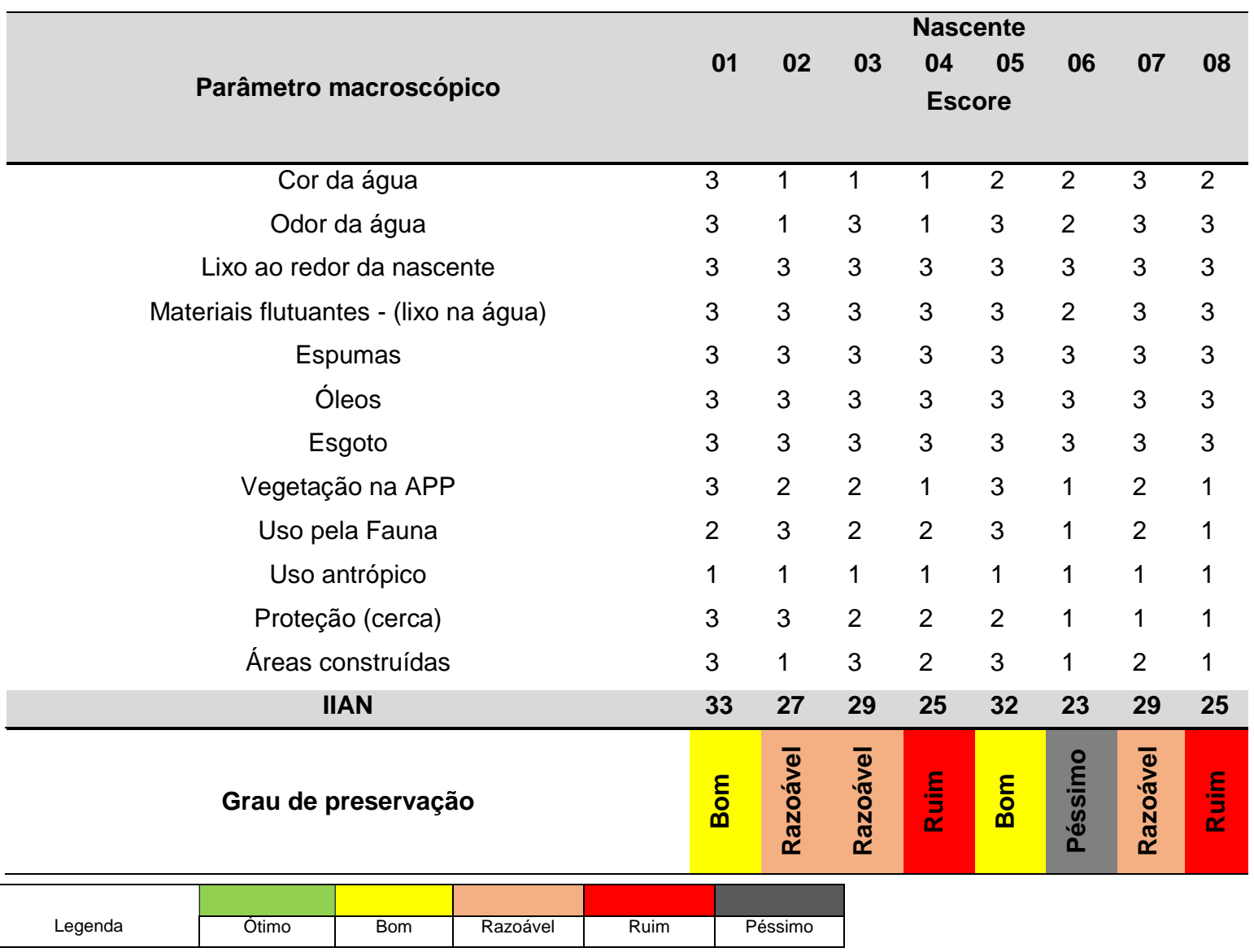

Fonte - Adaptado de Gomes et al. (2005).

Mesmo as nascentes que não apresentaram óleo, esgoto, lixo ou espumas, a falta de proteção ou a facilidade de acesso em algumas delas propicia a entrada de pessoas e animais. Desta forma, tais condições podem futuramente facilitar o surgimento de problemas na disposição irregular de lixo, degradando-as e dificultando a regeneração da vegetação (TORRES, 2016).

A análise do IIAN estabeleceu forte relação entre a proximidade com residências e a intensificação de degradação sofrida nos mananciais. De acordo com Leal et al. (2017), a proximidade com construções civis aumenta a probabilidade de impactos na qualidade ambiental das nascentes causados por ações humanas (LEAL et al., 2017). Acredita-se que essa proximidade também seja em parte responsável pela alteração de outros parâmetros avaliados: uso por animais, facilidade de acesso, degradação e antropização da vegetação. Assim sendo, é provável que a alteração desses parâmetros justifique a variação na cor e odor da água, como por exemplo, as nascentes 02,06 e 08 , as quais ficam a menos de cinquenta metros de áreas construídas. Duas delas (nascentes 06 e 08) tiveram seus graus de conservação classificados como "péssimo" e "ruim". As nascentes em questão não possuem cercas de proteção, a água é utilizada por animais das propriedades, notou-se alteração na cor e a vegetação encontra-se degrada ou ausente. A água da nascente 06 ainda possui cor escura e odor forte.

Quanto à cor da água, esta é resultado principalmente dos processos de decomposição que ocorrem no ambiente e de substâncias dissolvidas. Sua cor aparente é causada por matéria em suspensão, como o plâncton ou partículas suspensas, além de substâncias húmicas de origem orgânica que normalmente resultam em coloração amarela intensa ao reagir com o ferro (ABREU e CUNHA,2015). Colorações de tons de verde, azul-esverdeado, amarelo, marrom ou vermelho podem ser observadas conforme a densidade populacional de algas e bactérias, podendo ser um indício do fenômeno de 
eutrofização, bem como as partículas do solo em suspensão podem produzir muitas cores diferentes na água (BOYD, 2000).

No presente trabalho, $75 \%$ das nascentes estudadas tiveram sua coloração alterada, inclusive as nascentes 03 e 05 localizadas a mais de 100 metros das residências. No entanto, é importante destacar que embora a água da nascente 05 esteja protegida por uma cobertura improvisada por telhas de amianto, no momento de abertura para coleta, as folhas, galhos e pequenos insetos que ficam depositados sobre as telhas entram em contato com a água e podem ser os responsáveis pela sua coloração. Koch et al. (2017) ao avaliarem a qualidade da água destinada ao consumo humano em um município gaúcho observaram alteração da coloração de algumas amostras e relacionou-a à presença de material orgânico na água e/ou sais dissolvidos, como ferro e manganês. Os resultados das suas análises indicaram elevados valores de ácidos orgânicos, principais responsáveis pela coloração marrom-amarelada da água. Os autores citam outros materiais como areia e argila como influenciadores da turbidez e coloração da água.

A nascente 03 fica às margens da estrada vicinal do assentamento. Calheiros (2004) afirma que as estradas rurais não só expõem as nascentes ao acesso de pessoas, animais e trânsito de veículos, como é habitual serem projetadas justamente perto de rios e nascentes devido ao relevo mais favorável. A abertura de estrada em locais indevidos do terreno, além de proporcionar alteração da dinâmica hídrica, o solo fica exposto a diferentes processos erosivos causados pelas chuvas, deixando a superfície compactada e diminuindo a capacidade de infiltração do solo e, portanto, mais propício à formação de enxurradas. Desse modo, em virtude da localização da nascente, esta pode receber todo tipo de material que esteja próximo às margens da estrada. De fato, esse cenário justifica a poluição da água por partículas do solo de forma a alterar sua cor, tornando-a turva e/ou barrenta.

A vegetação nativa em pelo menos $75 \%$ das nascentes apresentava sinais de perturbação antrópica em situações de degradação ou ausência total. Foram identificadas ainda espécies invasoras em meio à paisagem natural, inclusive frutíferas e grande área de pastagem descaracterizando a vegetação local. Resultados semelhantes a esse foram encontrados por Corrêa et al. (2016), Marciano et al. (2016) e Silva et al. (2019), onde a maioria das APPs nas nascentes avaliadas encontravam-se em desacordo com a legislação. No assentamento houve supressão da vegetação em função do loteamento, deixando muitos mananciais ambientalmente vulneráveis. As nascentes dependem, dentre outras fontes, das águas provenientes das chuvas que infiltram no solo abastecendo o lençol freático. Portanto, a cobertura vegetal se faz necessária para que a água, ao invés de escorrer superficialmente, chegue às camadas mais profundas do solo.

O uso de APPs para fins produtivos é muito prejudicial ao ecossistema e à população humana, e por isso vê-se a necessidade de ações que promovam acesso à informação aos agricultores sobre a importância de preservar as APPs (COCCO et al., 2016). Nos estudos de nascentes no assentamento rural, Feitosa (2017) constatou que a vegetação predominante ao redor das nascentes se enquadrava em grande maioria com predominância de espécies de frutíferas e vegetação rasteira, seguido por monocultivo de cana-de-açúcar e vegetação rasteira. Resultados semelhantes aos de Machado e Soares (2018) ao qual destacou-se a vegetação rasteira e a vegetação rasteira associada às espécies frutíferas no entorno dos olhos d'água avaliados. Os autores ressaltaram a reflexão sobre ações de conservação in loco, principalmente para a garantia hídrica do assentamento.

Ao analisar as pontuações atribuídas às nascentes de vegetação alterada e as condições do cercamento delas (nascentes 02, 03, 04, 05, 06 e 08), acredita-se que esses parâmetros estejam intimamente ligados à falta de transparência das águas. Observa-se que das seis nascentes que manifestaram coloração alterada, cinco apresentam irregularidades se não em relação à vegetação, à cerca de proteção. A cor das águas das nascentes 02,03 e 04 foi caracterizada como escura, sendo as duas últimas com cercas, porém de fácil acesso a animais ou pessoas, além da vegetação apresentar-se alterada no caso da 03 e ausente na nascente 04. A inconformidade de cor também ocorreu com a nascente $02 \mathrm{e}$, embora o cercamento esteja dentro do recomendado, há uma expressiva alteração na mata nativa circundante.

A falta de APP, segundo Silva et al. (2018), atua como agravante para surgimento de escoamento superficial, diminuindo a infiltração e potencializando o risco de erosão nessas áreas, que por conseguinte pode aumentar o assoreamento dos corpos d'água. Além disso, , acarreta a contaminação da água por partículas do solo, sujando-a, ao passo que a vegetação exerce a função de proteção, filtragem, retenção de sedimentos e protege a diversidade local (GOMES et al., 2005). Segundo Palivoda e Povaluk (2015) a insuficiência de mata ciliar na referida área é determinante para a degradação de uma nascente, podendo ocasionar o baixo fluxo e a contaminação da água, os processos erosivos e por consequência, a extinção da nascente. Além de manter e conservar a cobertura vegetal, a área adjacente à nascente deve ser toda cercada, pois a ausência ou ineficiência da proteção potencializa uma extensa 
impermeabilização do solo, o que promove a descaracterização ou mesmo a destruição de grande parte das nascentes (FELIPPE e MAGALHÃES JUNIOR, 2012; REIS et al., 2012), bem como pode favorecer o lançamento de lixo doméstico e resíduos sólidos do meio rural na área e/ou na água.

No presente estudo $62,5 \%$ das nascentes encontram-se cercadas, a pontuação média entre elas é de 29,2 qualificando seu grau de conservação como "razoável". Em contrapartida, as nascentes desprotegidas assumem uma classificação "ruim" com 25,6 pontos. Percebe-se que a proteção da área ao redor das nascentes é uma prática importante em termos de conservação da área e representa possibilidade de melhoria na infiltração de água no solo e recarga dos lençóis freáticos, em função de não haver pisoteio do gado e compactação da área, aumentando a quantidade de água disponível e contribuindo para a qualidade dessas. Ademais, a estadia de animais na área e o uso da água provoca contaminação da nascente por fezes e urina.

Para Leal et al. (2017) os maiores impactos encontrados nas áreas das nascentes da bacia do córrego Itanguá, foram a presença tanto animal, a qual pode provocar a contaminação da água, pisoteio e revolvimento do solo, quanto a de espécies exóticas vegetal, por ocupar as áreas de preservação permanente destinadas à vegetação nativa e, assim, poder alterar o ciclo hidrológico e a regeneração natural no sub-bosque.

Em relação ao impacto causado pela presença ou proximidade de animais, observou-se que nas nascentes 06 e 08 do AFF o acesso e uso é livre, justificando os baixos valores atribuídos ao parâmetro "Uso pela fauna" e colaborando para que ambas somassem um escore reduzido. Da mesma forma ocorreu na nascente 04 , que embora não tenha apresentado evidências de uso, fica localizada próxima à área de pastagem com permanente presença de gado. Portanto, o pasto e os animais devem ser afastados ao máximo da nascente, pois, mesmo que os animais não tenham livre acesso à água, seus dejetos depositados sobre o solo, nos períodos de chuvas podem ser carreados para a água. Águas de nascentes podem ser facilmente contaminadas, devido à falta de proteção adequada no local do afloramento ou em suas proximidades. O comprometimento da qualidade da água para fins de abastecimento doméstico é decorrente, dentre outras fontes de poluição, do deflúvio superficial agrícola. Esta susceptibilidade pode ser ainda mais marcante em períodos de chuva, uma vez que nesse período a percolação é rápida dos microrganismos em direção à água subterrânea. A disposição não controlada de dejetos animais em solos é realidade no meio rural brasileiro, ocasionando contaminação ambiental e problemas de saúde pública (STOLF e MOLZ, 2017).

Devido à ausência de outro meio para obtenção de água para consumo, a utilização das nascentes do assentamento é feita de forma intensa e constante pelas famílias. Em todas as nascentes estudadas foi constatado uso antrópico das nascentes. Assim como observado por Gomes et al. (2005) e Machado e Soares (2018), os vestígios de uso pelos humanos, através de irrigação, consumo doméstico, trânsito, uso da área e para pastagem de animais, corroboram com os resultados do protocolo de avaliação macroscópica aplicado que revela relações conflitantes homem x natureza. A população local se configura como contribuinte principal por boa parte dos processos de degradação existentes, devido à utilização excessiva (BELIZÁRIO, 2015; MACHADO e BRAGA,2018). Esses usos feitos de forma incorreta ocorrem devido à falta de proteção, manutenção e pela proximidade com residências destas áreas (SILVA et al., 2019). Somado a isso, a falta de informação e comprometimento com a questão ambiental, dificuldade financeira, saneamento básico e infraestrutura são fatores sociais de interferências antrópicas que ocasionam aspectos negativos para a preservação desses locais (MENDONÇA, 2002).

\section{ANÁLISE ESTATÍSTICA}

O dendrograma exibido na Figura 3 é o resultado da análise de agrupamento pelo método de Ward, calculado a partir dos dados de todos os parâmetros obtidos para o período estudado. Conforme observase, formou-se dois grandes grupos, o primeiro com as nascentes 02,03 e 04 que tiveram o maior número de parâmetros em desconformidade com as legislações e o segundo, formado pelas nascentes 01, 05,06,07 e 08. Porém, não foi possível adotar os grupos formados para análise, visto que os possíveis agrupamentos só seriam indicados quando a similaridade alcançasse uma distância menor, diferente do apresentado nos resultados desse trabalho. Apesar dos grupos terem sido formados, dentro de cada grupo os indivíduos são expressivamente diferentes ( $>40)$, motivo pelo qual as nascentes passaram a ser analisadas de forma separada. As avaliações individuais levando em consideração o perfil próprio de cada uma das nascentes ocorreu devido as características bastante distintas entre elas (seus resultados físicos, químicos e biológicos, seus ambientes circundantes e, principalmente, as interferências antropogênicas, manejo da área, entre outros). Assim, permite-se um melhor entendimento da contribuição de cada fator sobre cada nascente. 
Figura 3 - Dendrograma dos grupos formados pelas nascentes em estudo.

Dendrograma (método de Ward)

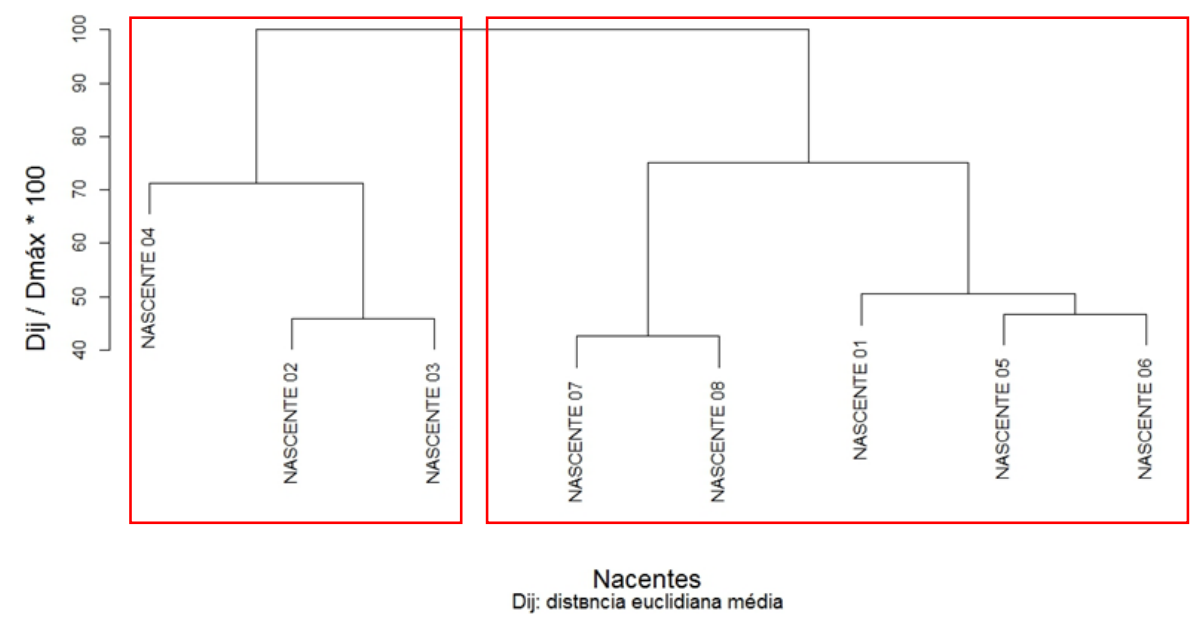

Fonte - Os autores.

Esta observação indicou que além dos aspectos espaciais, os resultados da variação da qualidade da água no período sazonal hidrológico parecem efetivamente influenciáveis e relevantes para as estratégias de monitoramento. Desconsiderar estes fatores pode resultar em erros metodológicos e de procedimentos para tomadas de decisão na gestão hídrica.

\section{QUALIDADE DA ÁGUA E CONFORMIDADE COM A LEGISLAÇÃO}

Os dados do monitoramento das variáveis inerentes à qualidade da água e sua conformidade com a legislação podem ser apreciados pela Tabela 3.

Tabela 3 - Valores médios dos parâmetros analisados nas oito nascentes em estudo e os valores determinados pela legislação.

\begin{tabular}{|c|c|c|c|c|c|c|c|c|c|c|}
\hline \multirow[b]{2}{*}{ Parâmetros Nascentes } & \multirow[b]{2}{*}{ N 01} & \multirow[b]{2}{*}{ N 02} & \multirow[b]{2}{*}{ N 03} & \multirow[b]{2}{*}{ N 04} & \multirow[b]{2}{*}{ N 05} & \multirow[b]{2}{*}{ N 06} & \multirow[b]{2}{*}{ N 07} & \multirow[b]{2}{*}{ N08 } & \multicolumn{2}{|c|}{ Normas } \\
\hline & & & & & & & & & $\begin{array}{l}\text { Portaria } \\
\mathrm{N}^{0} 2914\end{array}$ & $\begin{array}{l}\text { Resolucaão } \\
\mathbf{N}^{0} 357\end{array}$ \\
\hline $\mathrm{OD}\left(\mathrm{mg} \mathrm{L}^{-1}\right)$ & 8,20 & 3,63 & 3,87 & 4,23 & 3,21 & 6,02 & 3,53 & 4,67 & - & $\geq 5$ \\
\hline Temperatura $\left({ }^{\circ} \mathrm{C}\right)$ & 21,25 & 27,15 & 24,93 & 24,10 & 24,68 & 24,30 & 28,95 & 29,68 & - & - \\
\hline $\mathrm{pH}$ & 7,14 & 6,01 & 5,94 & 6,14 & 6,02 & 6,39 & 5,29 & 6,59 & 6,0 a 9,5 & 6,0 a 9,0 \\
\hline $\mathrm{COL}_{\text {totais }}(\mathrm{NMP} / 100 \mathrm{~mL})$ & 3300,00 & 2840,00 & 2260,00 & 4340,00 & 2700,00 & 3900,00 & 1600,00 & 1340,00 & Ausência & - \\
\hline $\mathrm{COL}_{\text {terme }}(\mathrm{NMP} / 100 \mathrm{~mL})$ & 240,00 & 380,00 & 880,00 & 360,00 & 80,00 & 20,00 & 40,00 & 180,00 & Ausência & $\leq 1000$ \\
\hline $\mathrm{DBO}\left(\mathrm{mg} \mathrm{L}^{-1}\right)$ & 0,94 & 0,92 & 0,75 & 1,36 & 0,52 & 1,81 & 0,74 & 0,89 & - & $\leq 5$ \\
\hline $\mathrm{N}$ Total $\left(\mathrm{mg} \mathrm{L}^{-1}\right)$ & 0,35 & 1,68 & 0,50 & 2,18 & 0,10 & 0,98 & 3,85 & 1,03 & $\begin{array}{l}\leq 10, \leq 1 \mathrm{e} \\
\leq 1,5^{(1)}\end{array}$ & $\begin{aligned} & \leq 10, \leq 1 \mathrm{e} \\
& \leq 3,7^{(1)}\end{aligned}$ \\
\hline P Total $\left(\mathrm{mg} \mathrm{L}^{-1}\right)$ & 0,54 & 0,17 & 0,05 & 0,53 & 0,10 & 0,07 & 0,67 & 0,37 & - & $\leq 0,1$ \\
\hline $\mathrm{Fe}\left(\mathrm{mg} \mathrm{L}^{-1}\right)$ & 0,10 & 1,68 & 2,56 & 1,11 & 0,13 & 0,78 & 0,26 & 0,28 & $\leq 0,3$ & $\leq 0,3$ \\
\hline $\mathrm{Ca}\left(\mathrm{mg} \mathrm{L}-{ }^{-} \mathrm{L}\right)$ & 2,50 & 10,00 & 2,50 & 0,75 & 0,00 & 0,00 & 0,00 & 2,50 & - & - \\
\hline $\mathrm{Mg}\left(\mathrm{mg} \mathrm{L}-{ }^{-} \mathrm{L}\right)$ & 1,25 & 2,50 & 5,00 & 2,50 & 0,00 & 1,25 & 1,25 & 1,25 & - & - \\
\hline Turbidez (UNT) & 3,83 & 19,44 & 8,03 & 26,83 & 11,27 & 12,32 & 2,72 & 1,84 & $\leq 5$ & $\leq 100$ \\
\hline $\mathrm{CE}(\mu \mathrm{S} / \mathrm{cm})$ & 38,23 & 25,94 & 24,52 & 64,58 & 49,70 & 46,78 & 75,45 & 75,38 & - & - \\
\hline Sólidos totais (mg L - ${ }^{1} \mathrm{~L}$ ) & 51,50 & 170,50 & 119,5 & 234,50 & 53,65 & 106,00 & 62,25 & 50,00 & - & - \\
\hline Sólidos dissolvidos (mg L - ${ }^{-} \mathrm{L}$ ) & 47,00 & 92,00 & 84,00 & 42,50 & 43,00 & 66,25 & 34,00 & 14,25 & $\leq 1000$ & $\leq 500$ \\
\hline Sólidos suspensos (mg L - ${ }^{-} \mathrm{L}$ ) & 4,00 & 78,50 & 35,50 & 192,00 & 21,00 & 39,75 & 28,25 & 31,25 & - & - \\
\hline
\end{tabular}

Fonte - Os autores.

$\begin{array}{llllll}\text { Caminhos de Geografia } & \text { Uberlândia-MG } & \text { v. 21, n. } 74 & \text { Abr/2020 } & \text { p. 276-294 Página } 287\end{array}$


Os resultados das análises mostraram baixas concentrações de oxigênio dissolvido, eles podem ser justificados pela própria natureza da água. Visto que as águas de nascentes têm sua origem subterrânea com pouco contato com a atmosfera, sendo esta e a fotossíntese as principais fontes de oxigênio (SPERLING, 2005; AGRIZZI et al.,2018). Outra justificativa apresentada por Galatto et al. (2011) é o fato das águas das nascentes estarem geralmente em ambiente redutor, diferentemente quando amostradas em águas de cursos d'água superficial, que se encontram em constante movimento.

As legislações discutidas nesse trabalho não estabelecem um padrão para a temperatura, porém Sperling (2005) destaca a importância de avaliar esse parâmetro no que diz respeito à influência ao aumento de reações químicas, físicas e biológicas. O aumento na temperatura da água causa mau cheiro devido à taxa de transferência de gases, tornando-a desagradável para o consumo. Diversos fatores são responsáveis pela alteração dessa variável: despejos domésticos, altitude, estação do ano, período do dia, taxa de fluxo e profundidade do manancial podem promover a variação da intensidade de calor durante um período (CETESB, 2009). Nesse trabalho, a diferença da temperatura provavelmente ocorreu devido à exposição da água ao sol, pela falta de sombreamento da área das nascentes, também evidenciado em nascentes no Assentamento Rural Paraíso em Alegre-ES, por Agrizzi et al. (2018), que encontrou valores mais elevados nas nascentes sem sombreamento.

Acredita-se que os pequenos valores de $\mathrm{pH}$ relativos à causas naturais, especificamente aos ácidos provenientes da decomposição da matéria orgânica da vegetação ou ao uso de agroquímicos que favorecem a contaminação das nascentes, alterando-o. No entanto, seguindo os preceitos de Sperling (2005), apesar dos resultados estarem abaixo dos exigidos pelas normativas, $\mathrm{o} \mathrm{pH}$ das nascentes estudadas esteve bem próximo disso ( $\geq 6)$. Essa pequena diferença, especificamente no caso do $\mathrm{pH}$, torna-se aceitável por não ser capaz de acometer danos a saúde humana.

Quando a água é utilizada para abastecimento humano, a Portaria de consolidação n.ำ 5/2017 estabelece, inclusive em poços e nascentes, que é obrigatório a ausência de bactérias do grupo Coliformes. Nas amostras desse trabalho houve constatação de coliformes totais e Escherichia coli em todas nascentes. No que diz respeito aos coliformes totais, foram constatadas altas concentrações e embora menores valores de E.coli, todas as nascentes estão em desacordo com a referida Portaria do Ministério da Saúde, visto que sua presença indica contaminação fecal. Em contrapartida, por não ultrapassarem 1000 NMP/100 mL-1, a maioria das nascentes atendem às exigências da Resolução CONAMA no 357/05 quanto aos registros de coliformes fecais. A presença de fezes na água pode indicar a existência de microrganismos, que ocorre por vários fatores. Em áreas rurais, destacam-se o destino do esgoto doméstico, a disposição inadequada de resíduos sólidos, a proximidade com fossas e áreas de pastagem ocupadas por animais. Além disso, o uso de resíduo orgânico animal no solo, como prática muito disseminada no meio rural, aumenta o risco de contaminação das águas subterrâneas (SCAPIN et al., 2012; CADONÁ et al., 2016).

A falta de rede de esgoto, saneamento ambiental e a coleta de lixo deficiente no Assentamento Florestan Fernandes, além do compartilhamento das nascentes com animais, expõem ainda mais as famílias a doenças resultantes da ingestão de alimentos e de água contaminada por bactérias, como a febre tifóide, disenteria, cólera, diarreia, hepatite, leptospirose e giardíase, citadas por Merten e Minella (2002), Teixeira et al. (2018) e UHR et al.(2016) como as principais enfermidades microbiológicas consequentes da carência do saneamento nas áreas rurais. Portanto, a partir dos resultados obtidos nas contagens de coliformes fecais, se comparados com o padrão exigido, é possível inferir que as amostras avaliadas das nascentes desse trabalho apresentaram baixa qualidade higiênico-sanitária para o período estudado.

Apesar do panorama do assentamento ser propício à altos valores de DBO, como uso e ocupação do solo na bacia, contaminação com resíduos agrícolas e criação de animais, as nascentes do presente estudo estiveram dentro dos valores máximos permitidos pela Resolução 357/05-CONAMA ( $\leq 5 \mathrm{mg} \mathrm{L}^{-1}$ ) para as águas subterrâneas, semelhante aos resultados obtidos por Pinto et al.(2012), Bomfim et al. (2015), que avaliaram as propriedades físicas, químicas e biológicas da água em nascentes situadas em Minas Gerais, além de Agrizzi et al. (2018) no Espírito Santo. Segundo esses autores, o valor de DBO aceitável retrata que a quantidade das necessidades respiratórias da população microbiológica para a decomposição da matéria orgânica presente foi suficiente.

Atividades agrícolas, esgotos domésticos, fertilizantes, excrementos de animais e presença de matéria orgânica oriunda de folhas, galhos e frutos são os principais contribuintes para a elevação nos valores de fósforo total em ambientes rurais (AGRIZZI et al., 2018; RODRIGUES et al., 2019). Mesmo com os valores de fósforo se apresentando acima dos limites do CONAMA, os autores afirmam que não necessariamente há poluição nas águas analisadas e sim resultados provenientes dos fatores naturais e/ou antrópicos. Os valores de fósforo obtidos no presente trabalho permitem propor uma verificação e indicar a existência de uma possível fonte poluidora responsável pelo distinto comportamento desses resultados amostrais. 
Assim como o fósforo, o fato de o nitrogênio ser proveniente também de excrementos animais e fertilizantes químicos (SPERLING, 2005), em especial às características do local de inserção da Nascente 07, a área de cultivos diversos e prática de olericultura com uso de estercos bovino como adubo, pode justificar os resultados obtidos. A degradação dos mananciais hídricos em áreas agrícolas ocorre, sobretudo pela eutrofização em decorrência do aporte de nitrogênio e fósforo proveniente das áreas agricultadas (SANTOS WEBER et al.; 2016, PINHEIRO et al., (2019).

A Nascente 01, que tem a cobertura vegetal mais preservada e está localizada em meio à mata nativa, apresentou os menores valores de ferro. Pesquisas demostram que a vegetação ciliar preservada atua na redução do teor de Ferro na água. À exemplo disso, Marmontel e Rodrigues (2015) alegaram em seus trabalhos que a presença da vegetação ciliar nas nascentes mostrou-se como um fator influenciador nas concentrações mais baixas desse parâmetro, tanto no período de seca quanto no período de chuva. Por sua vez, a nascente com presença da pastagem e a nascente com bambuzal na cabeceira mostraram que a ausência ou somente uma faixa da vegetação ciliar em estado degradado contribuiu para a elevação dos valores de ferro. Outros autores também encontraram maiores teores de ferro na água (AGRIZZI et al., 2018) em áreas semelhantes com pastagem no entorno e sem proteção ciliar, o que indica serem essas as fontes do maior teor de ferro. Além da má conservação do solo e ausência de APP, Santos et al. (2019), ao investigarem a variabilidade da qualidade hídrica e a relação com o uso do solo em uma bacia hidrográfica em Goiás, atribuíram os resultados encontrados às características dos solos da microbacia ricos em ferro e ao acúmulo desse elemento na água agravado no período seco. Portanto, considera-se válida a comparação com os autores supracitados, por não dispor de outra fonte de contribuição para esse parâmetro a não ser as características dos solos, que segundo o Instituto Capixaba de Pesquisa, Assistência Técnica e Extensão Rural - INCAPER (2011), a região apresenta predomínio de Latossolo Vermelho-Amarelo com altos teores de ferro.

O cálcio e magnésio possuem baixas toxicidades e, apesar de seus limites não serem padronizados pela legislação suas análises tornam-se importantes pois em altas concentrações tornam o sabor da água desagradável. Ademais, estes metais em teores adequados são características desejáveis para irrigação, por ajudar a manter boa estrutura e permeabilidade do solo (NUNES SILVA et al., 2011). Porém, as verificações nesse estudo em termos quantitativos não foram satisfatórias, visto que a maioria dos valores encontrados para cálcio e magnésio foram 0,00 $\mathrm{mg} \mathrm{L}^{-1}$. Segundo Pastro (2015), a presença desses metais pode estar inferior à capacidade de detecção de aparelhos utilizados nos laboratórios.

No geral a turbidez esteve dentro dos níveis estabelecidos pelo CONAMA 357/2005, onde o limite estabelecido para classe dois é de até 100 UNT, o qual não foi excedido em nenhuma das oito nascentes. Porém, para as exigências do Ministério da Saúde, o mesmo não se repetiu, visto que o limite máximo é de apenas 5 UNT. Um dos principais parâmetros de qualidade das águas capaz de demonstrar alterações na dinâmica hidrossedimentar de uma bacia como consequência da erosão acelerada é a turbidez (RAPOSO et al., 2009, apud LUÍZ et al., 2012, p. 293; HOFFMANN e OLIVEIRA, 2018). Em estudos de Medeiros et al. (2016) e Machado e Selva (2018) e as fontes em desconformidade para o parâmetro de turbidez pertenciam as nascentes com pastagem, indicando a ocorrência de erosão, como consequência da desestruturação do solo, ocasionada pelo manejo indevido da pastagem e, ainda, pela presença dos animais de criação que pisoteiam as nascentes e córregos gerando lama. Esse problema é agravado nas nascentes pela ausência de estruturas de proteção superior ou laterais, facilitando a entrada de sedimentos.

Altos valores de condutividade elétrica podem indicar características corrosivas da água, pois este parâmetro fornece uma boa indicação das modificações na composição de uma água, especialmente na sua concentração mineral, mas não fornece nenhuma indicação das quantidades relativas dos vários componentes (TAVARES et al. 2019; NASCIMENTO e GUEDES 2016). Para as nascentes dessa pesquisa os valores obtidos para condutividade elétrica não apresentaram muitas divergências entre elas.

Quanto a série de sólidos (sólidos totais, sólidos suspensos e sólidos dissolvidos), apenas os limites de sólidos dissolvidos estão previstos em lei. No período em que ocorreram as coletas, os valores em todas as nascentes indicaram baixas concentrações de sólidos dissolvidos, inferiores ao limite máximo (1000 $\mathrm{mg} / \mathrm{L}^{-1}$ ) estabelecido na Portaria $5 / 17$, estando dessa forma propícias ao consumo humano. Também mantiveram-se em conformidade para Resolução CONAMA 357/05, estando apta ao abastecimento humano, após tratamento convencional e uso na irrigação de hortaliças e frutíferas. Muito embora haja associação entre os parâmetros sólidos totais e turbidez, nem sempre eles são absolutamente equivalentes (AGRIZZI et al. 2018). Todavia, as nascentes com maiores médias para sólidos dissolvidos neste trabalho foram: a Nascente $02\left(92,0 \mathrm{mg} / \mathrm{L}^{-1}\right)$, a Nascente $03\left(84,0 \mathrm{mg} / \mathrm{L}^{-1}\right)$ e a Nascente $06(66,25$ $\left.\mathrm{mg} / \mathrm{L}^{-1}\right)$, coincidindo com os resultados de turbidez, exceto pela Nascente 03, que no caso de turbidez 
apresenta-se com valores medianos, de $8,03 \mathrm{mg}^{-\mathrm{L}^{-1}}$. Algumas propriedades específicas dessas nascentes ajudam a explicar, em partes, os resultados.

Em síntese, a nascente que esteve mais próxima do requerido pelas normativas e apresenta-se com valores inadequados somente para os parâmetros de coliformes e fósforo total foi a Nascente 01. Embora a presença de E.coli ter sido atribuída ao provável uso da água por animais silvestres da mata onde a nascente fica localizada, é importante monitora-la a fim de confirmar essa hipótese. As Nascentes 0203 e 04 tiveram os piores resultados em termos de potabilidade para o período em estudo. Estando em desacordo com os parâmetros oxigênio dissolvido, $\mathrm{pH}$, coliformes termotolerantes, fósforo total, ferro e turbidez.

Os parâmetros que mais estiveram fora dos padrões foram: oxigênio dissolvido, coliformes termotolerantes, ferro e turbidez. Todas as águas das nascentes no período contemplado por esse estudo estiveram em algum momento em desacordo com a legislação. Por isso, para que sejam utilizadas no abastecimento humano é imprescindível o tratamento de desinfecção prévio.

Em relação aos dados encontrados nessa pesquisa foi possível estabelecer uma interação entre a desconformidade com o padrão determinado na legislação brasileira e a caracterização hidroambiental das nascentes. Dado que a qualidade da água parece estar intimamente associada à influência da poluição difusa proveniente dos impactos ambientais encontrados, já que o IIAN indicou apenas $25 \%$ das nascentes enquadradas como "bom", sendo as demais com o grau de conservação variando de razoável a péssimo.

A problemática da potabilidade da água no Assentamento Florestan Fernandes não consiste em uma questão puramente técnica de proteção de mananciais, infraestrutura e cumprimento de legislações ambientais e florestais. É preciso trabalhar, dentro do possível, a mudança de hábitos da comunidade, no que diz respeito ao tratamento da água, ainda que simples como filtração, fervura ou cloração, até entendimento sobre métodos de coleta da água, limpeza da área das nascentes, destino de lixos, desinfecção das caixas d'água, métodos adubação menos agressivos, confecção de proteção física para as nascentes, entre outros. A qualidade da água não está restrita à técnicos e pesquisadores, mas à população, que ao mesmo tempo é responsável pela contaminação e sofre com suas consequências (BERNARDES, 2009). No entanto, o trabalho na implementação de todas essas ações, sejam elas técnicas ou de conscientização, emergenciais, mitigadoras ou preventivas, exigem participação de gestores públicos através de políticas governamentais e administrativas.

\section{CONSIDERAÇÕES FINAIS}

Fundamentado no conjunto de informações apresentadas nesta pesquisa, concluiu-se que o uso e ocupação do solo, bem como seu manejo influenciam na qualidade da água, principalmente para o abastecimento humano. As águas nascentes do AFF foram consideradas fora do padrão exigido pelas normativas do CONAMA e Ministério da Saúde. As variáveis analisadas que mais apresentaram condições incompatíveis com a legislação foram oxigênio dissolvido, $\mathrm{pH}$, coliformes, fósforo total e turbidez. A qualidade microbiológica das nascentes foi sensível à variação do uso e manejo do solo na bacia.

O IIAN mostrou duas nascentes com grau de conservação "bom"; três "razoáveis"; duas "ruim" e uma "péssimo". Estes parâmetros indicam a necessidade de ações de melhoria para a qualidade da água. As principais contribuições dessa pesquisa favorecem o conhecimento das nascentes, interpretação da diversidade de características existentes e identificação das causas e consequências das ações antrópicas sobre elas. Percebe-se que a caracterização hidroambiental de nascentes, embora realizado de forma macroscópica, consiste em uma metodologia eficaz para caracterização e diagnóstico, e é amplamente replicável em diferentes áreas, sob variadas condições. A inexistência de cercas de proteção das nascentes, uso e ocupação das áreas de preservação permanente de forma irregular e a proximidade com construções foram os principais aspectos que intensificaram a degradação do meio ambiente em questão.

É possível afirmar que dentro de cada agrupamento as nascentes são diferentes devido a suas peculiaridades.

\section{AGRADECIMENTOS}

O presente trabalho foi realizado com apoio da Coordenação de Aperfeiçoamento de Pessoal de Nível Superior - Brasil (CAPES) - Código de Financiamento 001. 


\section{REFERÊNCIAS}

ABNT - ASSOCIAÇÃO BRASILEIRA DE NORMAS TÉCNICAS. Preservação e técnicas de amostragem de efluentes líquidos e corpos receptores: NBR9898. . 1987, p. 22.

ABREU, C. H. M de.; CUNHA, A. C da. Qualidade da água em ecossistemas aquáticos tropicais sob impactos ambientais no baixo Rio Jari-AP: Revisão descritiva. Biota Amazônia, v. 5, n. 2, p. 119-131, 2015. https://doi.org/10.18561/2179-5746/biotaamazonia.v5n2p119-131

AGRIZZI, D. V.; CECÍLIO, R. A.; ZANETTI, S. S.; GARCIA, G. O.; AMARAL, A. A. F.; ELZIANE, F. A.; MENDES, N. G. S. Qualidade da água de nascentes do Assentamento Paraíso. Eng. Sanit. Ambient, Rio de Janeiro, v. 23, n. 3, p. 557-568, 2018. https://doi.org/10.1590/s1413$\underline{41522018150701}$

ANA - Agência Nacional de Águas. Cuidando das Águas: Soluções para melhorar a qualidade dos recursos hídricos. 2. ed. Brasília: Agência Nacional de Águas, Programa das Nações Unidas para o Meio Ambiente, 2013.

BECKAUSER, M. C.; NAKASHIMA, P.; SILVA, L. M. A utilização de análise macroscópica de nascente como ferramenta de Educação Ambiental. Revista Brasileira de Educação Ambiental (RevBEA), v. 14, n. 2, p. 252-267, 2019.n https://doi.org/10.34024/revbea.2019.v14.2635

BELIZÁRIO, W. da S. Avaliação da qualidade ambiental de nascentes em áreas urbanas: um estudo sobre bacias hidrográficas do município de Aparecida de Goiânia/GO. Revista Mirante, v. 8, p. 122148, 2015.

BERNARDES, A. de M. Uso e ocupação do solo e qualidade da água na bacia do córrego do Engenho, Viçosa, Minas Gerais.2009.81f. Dissertação (Mestrado em Solos e Nutrição de plantas) Universidade Federal de Viçosa, Viçosa, 2009.

BERTOSSI, A. P. A. et al. Qualidade da água em microbacias hidrográficas com diferentes coberturas do solo no sul do Espírito Santo. Revista Arvore, v. 37, n. 1, p. 107-117, 2013. https://doi.org/10.1590/S0100-67622013000100012

BOMFIM, E. O. et al. Sustentabilidade hidroambiental de nascentes na bacia do rio Gramame no Estado da Paraíba, Brasil. Sociedade \& Natureza, Uberlândia, v. 27, n. 3, p. 453-468, 2015. https://doi.org/10.1590/1982-451320150307

BOYD, C. E. Particulate Matter, Turbidity, and Color. In: Water Quality. Springer. 1. ed. Boston, MA: Springer, 2000. p. 95-103. https://doi.org/10.1007/978-1-4615-4485-2 6

BRASIL. Caderno de saneamento ambiental 5. Brasília: Ministério das Cidades, 2004.

BRASIL. MINISTÉRIO DO MEIO AMBIENTE. CONAMA - Conselho Nacional do Meio Ambiente. Resolução no 357, de 17 de março de 2005. Dispõe sobre a classificação dos corpos de água e diretrizes ambientais para o seu enquadramento, bem como estabelece as condições e padrões de lançamento de efluentes, e dá outras providências. Diário Oficial da União, p. 58-63, 17 mar. 2005.

BRASIL. MINISTÉRIO DA SAÚDE. Portaria de Consolidação № 5, de 28 de setembro De 2017. Disponível em <http://portalarquivos2.saude.gov.br/images/pdf/2018/marco/29/PRC-5-Portaria-deConsolida----o-n---5--de-28-de-setembro-de-2017.pdf>. Acesso em: 16 de novembro de 2019.

CADONÁ, E. A., DE SOUZA, E. L., GUERRA, D., BOHRER, R. E. G. Utilização de Adubação Orgânica com Dejetos de Suínos e Contaminação de Água e de Solo por Coliformes. Ciência e Natura, v. 38, n. 3, p. 1601-1609, 2016. https://doi.org/10.5902/2179460X22410

CALHEIROS, R. de O. Preservação e Recuperação das Nascentes (de água e de vida). 1. ed. Piracicaba: Comitê das Bacias Hidrográficas dos Rios PCJ-CTRN, 2004.

CETESB - Companhia Ambiental do Estado de São Paulo. Qualidade das águas interiores no estado de São Paulo. p. 1-43, 2009.

COCCO, J. et al. Análise do uso e cobertura da terra nas áreas de preservação permanente das nascentes da sub-racial de Mato Grosso-Brasil. Ciência e Natura, v. 38, n. 3, p. 1411, 28 set. 2016. https://doi.org/10.5902/2179460X22820 
CORRÊA, C. P.; TONELLO, K. C.; FRANCO, F. S. Análise hidroambiental da microbacia do PirajibuMirim, Sorocaba, SP, Brasil. Ambiente e Agua - An Interdisciplinary Journal of Applied Science, v. 11 , n. 4, p. 943,25 out. 2016. https://doi.org/10.4136/ambi-agua.1969

FEITOSA, L. C. M. Adequação metodológica para avaliação do potencial de conservação de nascentes rurais. 2017. 164f. Tese (Doutorado em Desenvolvimento e Meio Ambiente). Universidade Federal de Pernambuco: Recife. 2017.

FELIPPE, M. F.; MAGALHÃES JUNIOR., A. P. M. Impactos ambientais macroscópicos e qualidade das águas em nascentes de parques municipais em Belo Horizonte, MG. Geografias, v. 8, n. 2, p. 823, 2012.

FRANÇA JR, P.; VILLA, M. E. C. D. Análise macroscópica nas cabeceiras de drenagem da área urbana de Umuarama , região noroeste - Paraná. Geografia Ensino \& Pesquisa, v. 17, n. 1, p. 107117, 2013. https://doi.org/10.5902/223649948743

GALATTO, S. L. et al. Diagnóstico ambiental de nascentes no município de Criciúma, Santa Catarina. Revista de Ciências Ambientais, v. 5, n. 1, p. 39-56, 2011.

GEOBASES - Sistema Integrado de Bases Geoespaciais do Estado do Espírito Santo. Vitória, ES: IJSN. Disponível em: < https://geobases.es.gov.br/>.

GOMES, M. da C. R.; CAVALCANTE, I. N. Aplicação da análise estatística multivariada no estudo da qualidade da água subterrânea. Águas Subterrâneas, v. 31, p. 134-149, 2017. https://doi.org/10.14295/ras.v31i1.28617

GOMES, P. M.; MELO, C.; VALE, V. S. Avaliação dos impactos ambientais em nascentes na cidade de Uberlândia-MG: análise macroscópica. Sociedade \& Natureza, Uberlândia, v. 17, n. 32, p. 103120, 2005.

HOFFMANN, T. C. P.; OLIVEIRA, F. A. Influence of land use in rural and urban areas on the production and transport of suspended sediments in the drainage basin of the Capivari River, LapaPR. Revista Brasileira de Geomorfologia, v. 19, n. 4, p. 821-836, 2018. https://doi.org/10.20502/rbg.v19i4.1340

INCAPER - Instituto Capixaba de Pesquisa, Assistência Técnica e Extensão Rural. Guaçuí Planejamento e programação de ações. Espírito Santo: Instituto Capixaba de Pesquisa Assistência Técnica e Extensão Rural, 2011.

INCRA - Instituto Nacional De Colonização E Reforma Agrária. Incra nos Estados - Informações gerais sobre os assentamentos da Reforma Agrária. [On line] Brasília: INCRA, 2017. Disponível em: http://painel.incra.gov.br/sistemas/index.php. Acesso em: 28 de janeiro de 2020.

$\mathrm{KOCH}, \mathrm{F}$. F. et al. Análise de água superficial para consumo humano em um município do Rio Grande do Sul. Revista Caderno Pedagógico, v. 14, n. 1, 2017. https://doi.org/10.22410/issn.19830882.v14i1a2017.1398

LEAL, M. S.; TONELLO, K. C.; DIAS, H. C. T.; MINGOTI, R.Caracterização hidroambiental de nascentes. Revista Ambiente e Agua, v. 12, p. 146-155, 2017. https://doi.org/10.4136/ambiagua.1909

LUÍZ, A.M.E.; PINTO, M.L.C.; SCHEFFER, E. W.O. Parâmetros de cor e turbidez como indicadores de impactos resultantes do uso do solo, na bacia hidrográfica do rio Taquaral, São Mateus do SulPR. Raega - 0 Espaço Geográfico em Análise, v. 24, 2012. https://doi.org/10.5380/raega.v24i0.26264

MACHADO, F. B.; FERREIRA, A. M.; FRANCHI, T.; SILVA, R.C.F.; ASSIS, L.C. Relação da qualidade da água e cobertura da terra em microbacia antropizada do cerrado mineiro. Revista de Ciências Agroambientais, v. 14, n. 1, p. 28-36, 2016.

MACHADO, L. C.; BRAGA, R. A. P. Avaliação da Conservação de Nascentes no Assentamento Caricé no Estado de Pernambuco. Ciência e Sustentabilidade, v. 4, n. 1, p. 133-155, 2018. https://doi.org/10.33809/2447-4606.412018133-155

MACHADO, L. C.; SELVA, V. S. Avaliação do potencial de conservação de nascentes na Zona da Mata Pernambucana. Rev. Geama, v. 4, n. 1, p. 39-48, 2018. 
MACHADO, L. C.; SOARES, D. B. Caracterização de Nascentes da Bacia Hidrográfica do Rio Capibaribe em Assentamento Rural. Revista Geama, v. 4, n. 2, p. 5-12, 2018.

MARCIANO, A. G.; SILVA, L. F.; SILVA, A. P. M. Diagnóstico das nascentes da bacia hidrográfica do córrego do Vargedo. Revista Brasileira de Energias Renováveis, v. 5, n. 3, p. 330-342, 2016. https://doi.org/10.5380/rber.v5i3.48128

MARMONTEL, C. V. F.; RODRIGUES, V. A. Parâmetros Indicativos para Qualidade da Água em Nascentes com Diferentes Coberturas de Terra e Conservação da Vegetação Ciliar. Floresta Ambient., Seropédica, v. 22, n. 2, p. 171-181, 2015. https://doi.org/10.1590/2179-8087.082014

MEDEIROS, T. F., da SILVA, F. R., MORANDI, E. R., NASCIMENTO, P. C., DUTRA, A. R., STACHIW, R. Avaliação da qualidade de água de nascentes sob diferentes ocupações do solo. Revista Brasileira de Ciências da Amazônia/Brazilian Journal of Science of the Amazon, v. 4, n. 1, p. 14-28, 2016.

MENDONÇA, R. Como cuidar do seu meio ambiente. São Paulo: Bei Comunicação, 2002.

MERTEN, G. H.; MINELLA, J. P. Qualidade da água em bacias hidrográficas rurais: um desafio atual para a sobrevivência fututra. Agroecol. e Desenvol. Rur. Sustent, v. 3, n. 4, p. 33-38, 2002.

NASCIMENTO, F. E.; GUEDES, J. A. Qualidade ambiental do reservatório Cajá, Taboleiro Grande (RN). Revista Tamoios, v. 12, n. 1, 2016. https://doi.org/10.12957/tamoios.2016.19610

NUNES SILVA, Í. et al. QUALIDADE DE ÁGUA NA IRRIGAÇÃO. Agropecuária Científica no Semiárido, v. 7, n. 3, p. 1-15, 2011.

OLIVEIRA, M. C. DE P. et al. Avaliação macroscópica da qualidade das nascentes do campus da Universidade Federal de Juiz de Fora. Revista de Geografia-PPGEO-UFJF, v. 3, n. 1, 2013.

PALIVODA, A.; POVALUK, M. Avaliação do estado de conservação de nascentes localizadas em áreas rurais do município de Itaiópolis, SC. Saúde E Meio Ambiente: Revista Interdisciplinar, v.4, n.1, p. 17-31. 2015.

PASTRO, M. S. Qualidade da água em microbacias hidrográficas com diferentes coberturas vegetais. 2015. Dissertação (Mestrado em Ciências Florestais), Universidade Federal do Espírito Santo,Jerônimo Monteiro. 2015.

PINHEIRO, D. C; SALDANHA, E. C.; DO NASCIMxENTO MONTE, C. Índice de estado trófico e a proveniência do fósforo e clorofila-a em diferentes estações do ano em uma microbacia Amazônica. Revista Ibero-Americana de Ciências Ambientais, v. 10, n. 5, p. 89-100, 2019.

PINTO, L. V. A.; ROMA, T. N. DE; BALIEIRO, K. R. DE C. Avaliação qualitativa da água de nascentes com diferentes usos do solo em seu entorno. CERNE, v. 18, n. 3, p. 495-505, 2012. https://doi.org/10.1590/S0104-77602012000300018

REIS, P. E. et al. O escoamento superficial como condicionante de inundações em Belo Horizonte, MG: Estudo de caso da sub-bacia Córrego do Leitão, bacia do Ribeirão Arrudas. Geosciences = Geociências, v. 31, n. 1, p. 31-46, 2012.

REISSLER, J. MANZIONE, R. L. Classificação do uso da terra em área de afloramento do Sistema Aquífero Guarani entre 2002 e 2011: o caso da bacia do Ribeirão do Jacú, Tejupá/SP. Águas Subterrâneas, v. 30, n. 2, p. 172-189, 2016. https://doi.org/10.14295/ras.v30i2.28512

RODRIGUES, B. M., OSCO, L. P., ANTUNES, P. A., RAMOS, A. P. M. Avaliação da influência do uso e cobertura da terra na qualidade das águas superficiais da bacia hidrográfica do rio Pirapozinho (SP). Revista Brasileira de Geografia Física, v. 12, n. 03, p. 738-753, 2019. https://doi.org/10.26848/rbgf.v12.3.p738-753

SANTOS, G. O., RIBEIRO, R. L., PARREIRA, T. P., DA SILVA, D. F., SILVA, K. A., AZEREDO, C. F. Monitoramento da água em bacia hidrográfica com diferentes usos do solo no município de Rio Verde (GO). Revista em Agronegócio e Meio Ambiente, v. 12, n. 1, p. 249-271, 2019. https://doi.org/10.17765/2176-9168.2019v12n1p249-271

SANTOS WEBER, O. L., MIRANDA, S. O de., SANTOS, C. C dos., AMORIM, R. S. S., OLIVEIRA MOREIRA, $R$ de. Nitrogênio e fósforo nas águas proveniente de área de algodoeiro em dois sistemas 
de cultivos. Revista Brasileira de Ciências Agrárias, v. 11, n. 3, p. 186-191, 2016. https://doi.org/10.5039/agraria.v11i3a5383

SCAPIN, D.; ROSSI, E. M.; ORO, D. Qualidade microbiológica da água utilizada para consumo humano na região do extremo oeste de Santa Catarina, Brasil. Rev Inst Adolfo Lutz, v. 71, n. 3, p. 593-596, 2012.

SILVA, N. M. D. F da., DINIZ, R. G., FERREIRA, M. A. A., SANTOS, G. O., SANTOS, D. J. O. Condições ambientais das nascentes e mananciais do município de Rio Verde, Goiás. Global Science And Technology, v. 12, n. 2, 2019.

SILVA, T. G. N., COSTA GAMA, R., TEIXEIRA, L. G., SANTOS, G. R., SOUSA, R. M., SOUZA, P. B. DIAGNÓSTICO AMBIENTAL DE UMA ÁREA DE PROTEÇÃO PERMANENTE (APP), FORMOSO DO ARAGUAIA-TO. Revista da Universidade Vale do Rio Verde, v.16, n. 2, 2018. https://doi.org/10.5892/ruvrd.v16i2.4619

SIMEDO, M. B. L. et al. Effect of watershed land use on water quality: a case study in Córrego da Olaria Basin, São Paulo State, Brazil. Brazilian Journal of Biology, v. 78, n. 4, p. 625-635, 2018. https://doi.org/10.1590/1519-6984.168423

SOARES, A. B.; TROLEIS, A. L. Impactos ambientais na qualidade da água da nascente Pau Amarelo em Garanhuns-PE. Revista de Geografia (Recife), v. 34, n. 3, 2017.

SPERLING, M. Parâmetros de qualidade da água. Princípios do tratamento biológico de águas residuárias, p. 26-30, 2005.

STOLF, D. F.; MOLZ, S. Avaliação microbiológica da água utilizada para consumo humano em uma propriedade rural de Taió-SC. Revista Saúde e Meio Ambiente, v. 6, n. 1, p. 96-106, 2017. https://doi.org/10.24302/sma.v6i1.1104

TAVARES, L. C., DE ALMEIDA, I. R., DIAS, É. C., TEIXEIRA, L. G., FERNANDES, L. L. Avaliação da qualidade da água de abastecimento do campus saúde da cidade universitária José da Silveira Netto, Belém, Pará/Quality assessment of campus supply water health of the university city José da Silveira Netto, Belém, Pará. Brazilian Journal of Development, v. 5, n. 8, p. 11392-11404, 2019. https://doi.org/10.34117/bidv5n8-017

TEIXEIRA, Laize Eloy; BRANDÃO, Louise Francisca; SILVA, Florilda Vieira. Avaliação de custo e eficiência de três opções de tratamento de esgoto doméstico para unidade familiar na zona rural. Revista Expressão Científica (REC), v. 3, n. 2, p. 14-17, 2018.

TORRES, Fillipe Tamiozzo Pereira. Mapeamento e análise de impactos ambientais das nascentes do córrego Alfenas, Ubá (MG). Revista de Ciências Agroambientais, v. 14, n. 1, 2016.

UHR, J. G. Z.; SCHMECHEL, M.; UHR, D. A. P. Relação entre saneamento básico no Brasil e saúde da população sob a ótica das internações hospitalares por doenças de veiculação hídrica. Revista de Administração, Contabilidade e Economia da Fundace, v. 7, n. 2, 2016. https://doi.org/10.13059/racef.v7i2.104

Recebido em: 06/08/2019

Aceito para publicação em: 03/02/2020 